\title{
SUSTENTABILIDADE E AFETO: A DIMENSÃO AFETIVA DA SUSTENTABILIDADE NA FAMÍLIA
}

Risomar Gomes Monteiro Fialho ${ }^{1}$

Eduardo Vivian da Cunha ${ }^{2}$

Resumo: Este artigo propõe discutir sustentabilidade a partir da ideia de sua divisão em dimensões. Nesta perspectiva, aborda especialmente a dimensão afetiva da sustentabilidade, procurando buscar dentro desta a ligação existente entre a família e a sustentabilidade pela importância dos afetos que existem nesta relação. Trata através de pesquisa bibliográfica discutir especialmente de afeto entre os corpos individuais e coletivos, procurando entender de que maneira tais afetos circulam para determinar de que modos pode o sujeito dentro da família afetar e ser afetado e como estas afecções são capazes de tornar ou não um ambiente sustentável ou mesmo contribuir para a criação ou manutenção de espaços sustentáveis.

Palavras-chave: Sustentabilidade; Família; Afeto. 


\section{Introdução}

É consenso que a família precede todos os outros agrupamentos humanos, sendo sobremodo relevante estudá-la como fenômeno social relevante que é. Por esta razão, a história da família é indissociável da própria história do homem sobre a terra. Mas reduzir o estudo da família à sua formação social não dá conta de fenômeno tão complexo, uma vez que sobre ela incidem além das questões de cunho sociológico, outras tantas de cunho antropológico, biológico e jurídico. Uma abordagem que seja capaz de abranger minimamente sua citada complexidade há de ser, incontestavelmente, interdisciplinar.

A relevância do tema se dá sobretudo, porque permite aprofundar uma discussão acerca dos atores familiares no contexto do desenvolvimento sustentável e como o desempenho destes sujeitos influencia conceitos e ações sustentáveis ou insustentáveis, o que coloca os atores familiares como protagonistas do ambiente, fugindo de uma análise ambiental onde os sujeitos sejam apenas coadjuvantes.

Quanto aos seus fins, a pesquisa é exploratória e descritiva e quanto aos meios, uma pesquisa bibliográfica e telematizada, uma vez que se usou também conteúdo digital.

Assim, para definir a família como o objeto de estudo nesta pesquisa, não se pretendeu aqui regredir até as origens pré-históricas da família, uma vez que as bases deste fenômeno prescindem de unanimidade, o que tornaria o estudo pretendido um tanto mais complexo e infrutífero.

É certo que a complexidade dos arranjos familiares pressupõe a impossibilidade de tratá-la sob o prisma unicamente do afeto, uma vez que, ao falar da família, também nos reportamos a uma realidade social e institucional que é antes de tudo política. Nesta perspectiva, o que conhecemos como família é fruto de um conjunto de relações que envolvem normas definidas pelo Estado, relações de produção e trabalho, representações sociais no que diz respeito aos papéis masculinos e femininos e questões de cunho individual, construídas na subjetividade de seus integrantes.

Assim, com a presente pesquisa buscamos demonstrar quais as bases fundantes do conceito de sustentabilidade afetiva, partindo da elaboração e evolução do conceito de dimensões da sustentabilidade e qual o papel do afeto na construção de um desenvolvimento sustentável. Para isto, nos debruçamos sobre a família, buscando perceber como esta se comporta em relação à sustentabilidade e ao reconhecimento da necessidade de desenvolvimento sustentável e em que medida a família afeta e é afetada pelo meio em que está inserida. A tarefa não parece fácil nem passível de ser terminada, uma vez que tais questões estão sendo vivenciadas ao mesmo tempo em que estão sendo estudadas, numa construção extremamente dinâmica. $O$ trabalho pretende lançar luz sobre a discussão, mas sem a pretensão de encerrá-la. É muito mais uma provocação do que a sedimentação de um conceito. 


\section{Desenvolvimento sustentável, sustentabilidade e afeto: notas conceituais}

\section{Desenvolvimento sustentável}

O conceito de sustentabilidade e de desenvolvimento sustentável parece inicialmente ser de definição relativamente simples, uma vez que tal conceito vem sendo trabalhado por muitos autores de diversos espaços e áreas do saber. Mas para delimitar aquilo que pretendemos abordar, nos propusemos a estabelecer os conceitos-chave para o tema trabalhado e com este fim, procuramos estudar o significado de afeto, para então definir dimensão afetiva da sustentabilidade, tarefa que se realizou arduamente, pois a multiplicidade e profundidade do significado de afeto nos levou a uma inesperada dificuldade de defini-lo. Desta forma, preocupados em seguir um caminho lógico para alcançar de forma mais completa o objetivo pretendido, buscamos inicialmente definir desenvolvimento sustentável em seguida tratar de sustentabilidade e suas dimensões para, por fim, estabelecer em que consiste afeto e, consequentemente sustentabilidade afetiva.

Para a definição do que é desenvolvimento sustentável é preciso antes de tudo refletir nas razões pelas quais o conceito surge e estabelecer historicamente, o momento em que tal conceito se torna necessário para definir aspectos da vida do homem e sua relação com o mundo que o cerca.

$\mathrm{O}$ tema do meio ambiente surge historicamente num momento em que os países experimentam um crescimento econômico sem precedentes. Assim, esta preocupação aparece mais acentuadamente e ganha contornos ampliados após a Segunda Guerra Mundial. O modo de vida então baseado na industrialização e na urbanização levam a uma destruição ambiental, como a face maléfica de um modelo econômico cujas bases ignoraram solenemente os riscos ao planeta. Imaginava-se no pós-guerra que o progresso era certamente o caminho a ser percorrido pela sociedade, cuja vida seria melhorada pelo alcance de altos níveis de crescimento econômico.

Naturalmente que tal idéia não sobrevive sem vozes dissonantes, as quais começam a enxergar a face sombria deste crescimento econômico e o alto preço a ser pago por ele, sobretudo o aprofundamento das desigualdades e o risco ao planeta. Assim, se dá o surgimento de movimentos na Europa e Estados Unidos inicialmente, relacionando economia e meio ambiente e a influência direta da ação do homem sobre a natureza e acabam por promover o surgimento em todo o mundo de diversos movimentos em prol de um desenvolvimento que agredisse menos o meio ambiente. Tais movimentos uniam pessoas de diferentes ideais, que convergiam para discutir a relação do homem com o meio, traçando os contornos iniciais do que se convencionou chamar de ambientalismo.

Conforme RADOMSKY(2013,p.157)

Revbea, São Paulo, V. 13, № 4: 313-333, 2018.

revista brasileira

educação ambiental 
No final da década de 1970, é fundado na Alemanha o "partido verde", que aglutinava membros do movimento estudantil e da esquerda marxista, além de uma gama de ativistas tais como os ligados aos direitos dos homossexuais, feministas e militantes antinucleares. Uma década após quase todos os países europeus já tinham "partidos verdes".

Desta forma, grupos os mais diversos passam a propor reformas ambientais, pressionando os partidos políticos e chamando a atenção para vários problemas de ordem ambiental.

Ainda na década de 1970, precisamente em 1972, ocorre em Estocolmo - Suécia, a Conferência das Nações Unidas sobre o Meio Ambiente; evento cuja principal contribuição foi demonstrar ao mundo a gravidade da questão ambiental vivida, gerando uma declaração sobre o meio ambiente em que se instava os países de todo mundo a criar meios para a conservação da natureza e tratava incisivamente sobre questões de cunho econômico, ao afirmar que o subdesenvolvimento seria a causa dos problemas ambientais de muitos países e que era preciso superar o subdesenvolvimento para alcançar a redução da pobreza. De acordo com Veiga (2006 p. 115), esta foi a primeira vez em que se debateu meio ambiente como uma questão mundial e com a preocupação de preservar o meio ambiente pensando nesta e na geração futura.

De certa forma, como uma consequência desta primeira conferência, a ONU propõe uma nova conferência, cujo objetivo seria viabilizar, através de ações mais concretas, soluções para os problemas ambientais. Assim, nasce a ideia da Conferência da ONU sobre Meio-ambiente e desenvolvimento (Eco92) No Rio de Janeiro, que também ficou conhecida como Cúpula da Terra, onde diversos líderes mundiais se reúnem para discutir formas de promoção de Desenvolvimento Sustentável a nível global.

Conforme Viola e Franchini (2012, p. 7),

construída sobre um acumulado de duas décadas, a Rio 92 foi o ponto mais alto de gestão cooperativa dos recursos ambientais comuns, não apenas porque gerou cinco instrumentos normativos relevantes (as Convenções de Mudança do clima, de Biodiversidade, e de Desertificação, a Declaração do Rio, e a Agenda 21), mas porque foi rodeada por um clima de otimismo em relação à evolução da governança global. O valor da Rio 92 é alto, ainda que os instrumentos por ela criados não tenham refletido de forma suficiente o consenso científico da época e tivessem poucos efeitos práticos nos anos sucessivos. 
sustentável, conciliando métodos de proteção ambiental, justiça social e eficiência econômica.

Com o fito de viabilizar a primeira Conferência, que só viria a acontecer em 1992 no Rio de Janeiro, a ONU cria uma comissão para preparar um documento importantíssimo para o conceito de desenvolvimento sustentável, que ficou conhecido como Relatório Brundtland, por ter sido elaborado pela comissão que era supervisionada por Gro Harlem Brundtland, que então era primeira-ministra da Noruega.

O relatório é denominado "Nosso futuro comum" e nele, a presidente da comissão enfatiza que o desenvolvimento sustentável adquire legitimidade e institucionalização normativa. Assim, o relatório define desenvolvimento sustentável como aquele capaz de garantir as necessidades presentes sem comprometer a capacidade das gerações futuras de suprir as suas necessidades (BRUNDTLAND, 1991).

Além de conceituar desenvolvimento sustentável, o relatório também aponta as incompatibilidades entre este e o consumo exacerbado, além do papel dos países desenvolvidos num modelo de produção industrial que destrói o meio ambiente e que é reproduzido pelos países menos desenvolvidos.

Apesar de ser um marco no que respeita, sobretudo ao conceito criado, o Relatório Bruntdland recebe críticas pelo fato de não haver estabelecido realmente em que consiste esta sustentabilidade, a quem é direcionada e o que pretende.

Ao tratar destas críticas, esclarecedora é a reflexão trazida por Veiga (2008, p. 165) acerca da sustentabilidade:

Sendo uma questão primordialmente ética, só se pode louvar o fato da ideia de sustentabilidade ter adquirido tanta importância nos últimos vinte anos, mesmo que ela não possa ser entendida como um conceito científico. A sustentabilidade não é, nunca será, uma noção de natureza precisa, discreta, analítica ou aritmética, como qualquer positivista gostaria que fosse. Tanto quanto a ideia de democracia - entre muitas outras ideias tão fundamentais para a evolução da humanidade, ela sempre será contraditória, pois nunca poderá ser encontrada em estado puro.

A sustentabilidade tem sido estudada por campos diferentes do conhecimento e na perspectiva de diversos sujeitos, fazendo com que uma definição exata não seja alcançada e possivelmente sequer necessária. O que se tem observado é que de certa forma seu conceito inicialmente pareceu privilegiar questões de cunho econômico em detrimento de questões sociais, quando se trata de desenvolvimento sustentável, o que nos conduz às críticas já citadas acerca da lacuna conceitual e também como a expressa por Foladori (2001 p. 117) acerca da apropriação da ideia de desenvolvimento sustentável pelo mercado, modificando seu real sentido:

Revbea, São Paulo, V. 13, № 4: 313-333, 2018.

revista brasileira educação ambiental 
O desenvolvimento sustentável continua basicamente atrelado a um desempenho técnico, dentro das regras do jogo do sistema de mercado capitalista, sem atingir nem questionar as relações de propriedade e apropriação capitalistas, que geram pobreza, diferenciação social e injustiça [...].

De certa forma, pode-se dizer que o relatório Brundtland define melhor o que é sustentabilidade do que desenvolvimento sustentável, pois quanto a este último, se resume apenas a determiná-lo como sendo a satisfação das necessidades presentes e futuras. A crítica que se faz à sua apropriação pelo mercado e à ideia de satisfação de necessidades apenas econômicas baseiase justamente no fato do conceito de necessidade ser tão genérico.

Assim, quando se traz aqui a dimensão afetiva da sustentabilidade como tema de pesquisa, quer se pensar em desenvolvimento sustentável para além das questões de cunho econômico e ambiental, percebendo-se que os afetos alteram o espaço comum. É impossível não se dar conta de que questões estreitamente ligadas aos afetos, como gênero, violência contra a mulher, abandono de crianças, corrupção, falta de educação, desemprego e tantos outros influem e são capazes de gerar ambientes insustentáveis.

O que se pretende não é excluir a questão econômica da discussão sobre desenvolvimento sustentável posto que isto não seria possível, mas ampliar a percepção para discutir questões igualmente relevantes, inclusive economicamente, tais como justiça social, desenvolvimento regional, respeito ao patrimônio cultural, e acima de tudo, percebendo o papel do sujeito.

Furtado, (1984, p. 63), escrevendo sobre desenvolvimento, já traz a ideia de que este não precisa nem deve ser visto apenas por seu aspecto puramente econômico, sem levar em consideração os homens e sua capacidade de transformação do espaço com o objetivo de satisfazer suas necessidades. Ao discorrer sobre estas questões, ele afirma:

A visão que tenho do desenvolvimento é a de um processo criativo, de invenção da História pelos homens, em contraste com o quadro mimético e repetitivo de que são prisioneiras as sociedades dependentes. Em nossa civilização, o processo de desenvolvimento se faz com crescente ampliação da base material da cultura e também com enriquecimento do horizonte de expectativas do ser humano. Desenvolver-se é ascender na escala de realização das potencialidades dos homens como indivíduos e como coletividade.

Sen (2010, p.18), por sua vez, traz um pensamento inovador e interessante ao pretender discutir a questão posta, apresentando desenvolvimento como liberdade. Com isto, defende a ideia de que este só é possível removendo as principais formas de privação da liberdade dos sujeitos, a saber: a pobreza e a tirania, carência de oportunidades econômicas e 
destituição social sistemática, negligência dos serviços públicos e intolerância ou interferência excessiva de Estados repressivos..

A influência do pensamento de Sen é também demonstrado nos escritos de Veiga (2008), que não foge da premissa de que é preciso ampliar as liberdades para efetivamente se alcançar desenvolvimento:

A despeito de aumentos sem precedentes da opulência global, o mundo atual nega liberdades elementares a um grande número de pessoas, talvez até à maioria. Às vezes, a ausência de liberdades substantivas relaciona-se diretamente com a pobreza econômica, que rouba das pessoas a liberdade de saciar a fome, de obter uma nutrição satisfatória ou remédios para doenças curáveis, a oportunidade de vestir-se ou morar de modo apropriado, a possibilidade de ter acesso à água tratada ou saneamento básico.

O Desenvolvimento Sustentável em resumo, é aquele que leva em consideração as questões de ordem econômica mas não apenas elas. Ao discutir desenvolvimento como possibilidade de libertação ampliada dos sujeitos, percebemos o quão múltiplo pode ser o conceito. Assim, arremata Sen (2000 p.49):

Ver o desenvolvimento a partir das liberdades substantivas das pessoas tem implicações muito abrangentes para nossa compreensão do processo de desenvolvimento e também para os modos e meios de promove-lo. Na perspectiva avaliatória, isso envolve a necessidade de aquilatar os requisitos de desenvolvimento com base na remoção das privações de liberdade. Embora essa história não seja de modo algum desvinculada do processo de crescimento econômico e de acumulação de capital fixo e humano, seu alcance a abrangência vão muito além dessas variáveis.

Isto posto, como forma de se encontrar um caminho que leve em consideração tanto aspectos econômicos quanto humanos e ambientais, encontramos o pensamento de Ignacy Sachs para quem, desenvolvimento realmente sustentável leva em consideração desenvolvimento econômico, social e ambiental, afirmando a ideia de solidariedade tanto para com a geração atual quanto para com as gerações futuras. Falando desta solidariedade, afirma Sachs (2004, p.15) que:

Ela nos impele ainda a buscar soluções triplamente vencedoras, eliminando o crescimento selvagem obtido ao custo de elevadas externalidades negativas, tanto sociais quanto ambientais. 
O desenvolvimento nesta perspectiva, como imaginado por ele, teria um conteúdo ético indissociável, cujo olhar estaria voltado tanto para o presente quanto para o futuro.

\section{Sustentabilidade}

O conceito de sustentabilidade está intimamente ligado ao conceito de desenvolvimento sustentável, vez que se passa a discutir sustentabilidade ao mesmo tempo em que se discute desenvolvimento, ainda no âmbito das discussões iniciais da década de 1970, na criação dos chamados partidos verdes e segue a discussão ao longo da história, ampliando e definindo em que consiste desenvolver com sustentabilidade.

Para estabelecer um conceito de sustentabilidade, é preciso analisar como surge efetivamente o termo. Segundo Brusecke (1996), é Maurice Strong, secretário da conferência de Estocolmo, quem usa pela primeira vez o conceito de ecodesenvolvimento para definir o desenvolvimento como um modelo político alternativo à ideia de uma visão meramente econômica. Com relação aos princípios fundamentais em que se funda o ecodesenvolvimento, estes são formulados por Ignacy Sachs em 1993, apropriando-se do conceito de ecodesenvolvimento, pensa que sustentabilidade "trata-se de gerir a natureza de forma a assegurar aos homens de nossa geração e a todas as gerações futuras, a possibilidade de se desenvolver" (SACHS, 1986, p.14).

A sustentabilidade como imaginada por Sachs, possui um modelo conceitual holístico, cujo conector seria o meio ambiente que liga uns aos outros e possibilita aos seres humanos experimentar este espaço comum, construindo e modificando o seu entorno.

Partindo desta visão holística, temos que só seria possível discutir e implantar sustentabilidade tratando-a a partir de dimensões, que quando ordenadas, trariam a possiblidade de alocar os recursos de forma equitativa desenvolvendo não só o meio ambiente, mas todas os aspectos da vida dos indivíduos. Nesta perspectiva, sustentabilidade é vista como equilíbrio, não só entre o homem e o planeta, mas entre os homens. Enxergar o homem e o planeta como indissociáveis, envolve pensar soluções conjuntas que podem ser aplicadas a qualquer dimensão de necessidades humanas e também aos ecossistemas. Envolve ainda pensar em coisas como exercício da cidadania, consciência de si e do outro e civilidade, por exemplo, como questões indissociáveis dos problemas de ordem ambiental.

Quando Sachs, procurou inicialmente definir sustentabilidade a partir de dimensões, ele as dividiu em número de cinco, quais sejam: dimensão social, dimensão econômica, dimensão ecológica, dimensão espacial e dimensão cultural. Posteriormente, amplia estas dimensões e passa a considerar dimensões de sustentabilidade, quais sejam: ambiental, econômica, social, cultural, espacial, psicológica, política nacional e política internacional. 
A dimensão política da sustentabilidade afirma os processos participativos democráticos no diálogo com o Estado. Esta ampliação se fez por entender-se que sustentabilidade se estabelece também e primordialmente com a contribuição da população, mas também engloba o papel do Estado como ente formulador de políticas públicas, sem as quais se inviabilizaria o processo de construção de um mundo sustentável, ao se levar em conta as populações menos favorecidas e carentes de oportunidades.

Mesmo quando se busca imaginar sustentabilidade apenas sob uma perspectiva inicialmente ambiental, esta está imiscuída em questões eminentemente políticas uma vez que, mesmo que a distribuição dos recursos naturais se faça geograficamente sem uma ação direta do Estado, como as jazidas de metais ou petróleo, por exemplo, a distribuição social destes recursos é em última instância uma decisão política.

Sobre isto nos esclarece Bursztyn (2001, p. 109/110):

Um exemplo desta situação no Brasil são os debates e as disputas em redor da transposição das águas do rio São Francisco. O curso do rio é um fato de geografia e de geologia, mas a distribuição de suas águas representa uma clara decisão política. Deve essa água ser utilizada para irrigação? No caso de uma afirmação positiva, para que pessoas? Em quais Estados? Deve essa água ser utilizada como água potável? Para que cidades? A que distância do leito do rio? Cem quilômetros? Mil quilômetros? Ou talvez essa água não deva ser transposta, para ser utilizada somente para as pessoas que moram no vale do rio, como os pescadores e ribeirinhos? Todas estas perguntas somente podem ser respondidas por meio de decisões políticas.

De igual modo, é necessário pensar em dimensão política da sustentabilidade no âmbito da política internacional, uma vez que as decisões políticas no âmbito externo atingem e, muitas vezes inviabilizam a tomada de decisões que sejam capazes de melhorar a vida das pessoas no âmbito interno de cada país.

Ao discutir racionalidade ambiental na perspectiva de Estado e Sociedade, Leff (2006, p. 241/242) fundamenta a tese de que a resolução de problemas ambientais e desenvolvimento sustentável também do ponto de vista econômico não pode olvidar esta dimensão política. Nos seus dizeres, esta racionalidade implica na ativação de um conjunto de processos sociais. Que segundo ele envolvem:

A socialização do acesso e a apropriação da natureza; a democratização dos processos produtivos e do poder político; as reformas do Estado que the permitam medir a resolução de conflitos de interesse em torno da propriedade e aproveitamento dos recursos e que favoreçam a gestão participativa e descentralizada dos 
recursos naturais (...) A construção de uma racionalidade ambiental é um processo político e social, que passa pela confrontação e concertação de interesses opostos; pela reorientação de tendências( dinâmica populacional, crescimento econômico, padrões tecnológicos, praticas de consumo); pela ruptura de obstáculos epistemológicos e barreiras institucionais.

Daí percebe-se claramente que é necessário reordenar o papel que o Estado possui nesta equação e a importância de se discutir uma dimensão política de sustentabilidade. Embora se tenha preferido discorrer inicialmente acerca da dimensão política da sustentabilidade, esta escolha não teve o fito de diminuir a importância das demais, o que se fez foi apenas justificar a ampliação das dimensões para alcançar a dimensão política.

No que tange a estas dimensões, apesar de ser lgnacy Sachs o responsável por indica-las inicialmente, elas não são taxativas, uma vez que se discute sustentabilidade em dimensões múltiplas, inclusive dimensão geográfica e psicológica, que se justificaria pelo fato de ser a responsável por ligar o indivíduo às demais dimensões. Por esta razão, não se pode sequer fechar um conceito em torno de quantas efetivamente seriam as dimensões da sustentabilidade, mas é certo que a divisão incial feita por Sachs norteia as possibilidades de ampliação das demais.

Com base na divisão feita por Sachs, define-se sustentabilidade pelas suas dimensões da seguinte forma:

Sustentabilidade ecológica diz respeito á preservação dos recursos naturais pela limitação da utilização dos recursos não-renováveis bem como na produção de recursos renováveis, assim como a substituição de recursos maléficos ao planeta, por outros que não causem danos ambientais. Além disto, técnicas como reciclagem, limitação do consumo e desenvolvimento e utilização de tecnologias limpas também fazem parte desta dimensão;

Sustentabilidade territorial ou espacial leva em consideração uma distribuição equilibrada das atividades econômicas e ocupação urbana e rural, melhorias no ambiente urbano, superação das diferenças regionais limitadoras, bem como a criação de medidas que possam proteger ambientes frágeis do ponto de vista ecológico;

Sustentabilidade econômica trataria de desenvolvimento econômico equilibrado, construído a partir de uma análise que leve em conta questões macrossociais, para além de apenas a possibilidade de lucro, desenvolvendo uma economia solidária em detrimento de uma economia de mercado, autonomia científica e tecnológica além de inserção na economia internacional;

Sustentabilidade social abrangeria recursos de ordem material e não material, distribuição justa de renda, acesso aos serviços sociais, à justiça, garantia de direitos e ampliação da homogeneidade social, com empregos que garantam qualidade de vida à população;

Revbea, São Paulo, V. 13, № 4: 313-333, 2018. 
Sustentabilidade cultural, construída a partir do respeito às tradições e cultura de cada espaço e pela preservação destes bens sem descuidar da inovação.

E, por fim, a sustentabilidade política que, do ponto de vista da política nacional, se daria com o respeito aos direitos humanos, à democracia, à saúde do Estado e sua capacidade de capitanear junto aos empreendedores projetos que garantam coesão social e a criação de políticas públicas que fortaleçam a autonomia dos sujeitos. Já no âmbito internacional, diz respeito à construção de uma cultura de paz, à redução dos conflitos e à prevenção destes, a gestão do patrimônio global, o respeito e a manutenção da biodiversidade, da diversidade cultural, bem como a cooperação tecnológica e científica internacional.

\section{Afeto e dimensão afetiva da sustentabilidade na família}

Uma das questões principais que esta pesquisa busca discutir diz respeito à dimensão afetiva da sustentabilidade. Mas é preciso deixar claro que não há a possibilidade de se discutir as dimensões da sustentabilidade de forma isolada, uma vez que esta pluridimensionalidade só pode ser adequadamente tratada se imaginarmos que há elos invisíveis e indissociáveis que ligam todas elas, os quais só conseguiremos entender adequadamente se abordarmos o tema de maneira transdisciplinar e ampliada.

Dito isto, se faz necessário estabelecer em que consiste esta dimensão afetiva uma vez que ela não aparece na divisão clássica feita por Inagcy Sachs, pelo menos não de modo explícito.

Adélia Brasil (2013, p.143) assim define a dimensão afetiva da sustentabilidade:

A dimensão afetiva trata da natureza emocional capaz de unir organização e indivíduo, devido à realização das necessidades pessoais e expectativas gerais do ser humano enquanto um ser que vivencia a emoção, o sentimento e a prática do cuidado.

Em busca do conceito de afeto, deparamo-nos com uma construção muito mais complexa e ampliada do seu significado do que comumente imaginamos.

Para dar conta da apropriação exata do conceito, procuramos estabelece-lo inicialmente a partir de bases filosóficas. Nesta perspectiva, o conceito de sustentabilidade afetiva se apreende a partir de uma visão bem ampliada, pois leva em conta ainda o movimento dos corpos políticos, além dos próprios afetos individuais.

Assim, pretendemos aqui ultrapassar um conceito usual e extremamente reduzido de afeto, como sendo a simples demonstração da emoção, no sentido

revista brasileira educação ambiental 
mais contido que se pretende ao termo para, de forma mais abrangente, tratálo do ponto de vista filosófico e assim inseri-lo na esfera da sustentabilidade.

Com isto, não queremos excluir a noção de afeto como emoção, como experimentação incorpórea, mas ampliar-lhe o sentido para alcançar outras conceituações igualmente importantes.

No mundo globalizado, parece não haver espaço para a percepção individualizada do ser e aparentemente homens e mulheres, não existem em sua individualidade, mas são formados como uma imensa massa que pensa coletivamente, que constrói hábitos coletivos, que uniformiza modos de viver, pensar e agir, conduzindo à coisificação do sujeito e a um completo alheamento dos caminhos percorridos para estabelecer a sociedade em que os indivíduos se movem e existem.

O individualismo e não a individualidade é a marca do tempo presente. Não o outro não importa enquanto ele não é visto como primordial à satisfação de uma necessidade ou à resolução de um problema. As relações artificiais, plásticas, são a tônica da vida moderna a ponto de não se perceber como cada sujeito afeta e é afetado individual e coletivamente no relacionamento com o outro e com o meio. É, pois, nesta perspectiva que pretendemos discutir afetividade: a possibilidade de modificações mútuas a partir das afecções dos corpos.

Buscando o conceito de afeto para compreender a capacidade dos sujeitos de afetar e ser afetado, encontramos nos escritos de Espinoza definição mais significativa de afeto: "Por afeto compreendo as afecções do corpo, pelas quais sua potência de agir é aumentada ou diminuída, estimulada ou refreada, e, ao mesmo tempo, as ideias dessas afecções"( p.163). Espinoza reconhece assim três afecções primárias quais sejam: alegria, tristeza e desejo. Para ele, todas as outras afecções nascem a partir destas três.

Mais claramente posto, estas afecções seriam a forma como os corpos são afetados uns pelos outros. Neste sentido, os corpos afetam e são afetados mutuamente não só por afetos alegres, mas também por afetos tristes. Ademais, estes afetos se constroem não só internamente mas, a maneira como o mundo está disposto também influencia no surgimento e percepção destes.

Espinoza denomina potência, como o poder de afetar e ser afetado, ou seja, o poder que um corpo exerce sobre o outro. A potência de agir, portanto, seria aumentada ou diminuída, conforme a qualidade dos afetos, sejam alegres ou tristes.

Portanto, pode o homem viver de duas formas distintas: passivamente, se entregando aos encontros e não procurando modifica-los para buscar mais alegrias do que tristezas, ou viver ativamente, racionalmente procurando orientar seus encontros para viver os afetos alegres. Analisado desta forma, pode-se atribuir aos afetos alegres a ideia de liberdade e ação e aos afetos tristes a ideia de subordinação e passionalidade (Deleuze, 2002) 
Assim, tratar de dimensão afetiva da sustentabilidade, é pensar como somos afetados atualmente e como podemos ser afetados de forma diferente para produzirmos novas formas de viver, de pensar e de agir, uma vez que se somos afetados apenas de um modo específico, produziremos sempre o mesmo comportamento. Deste modo é fundamental estabelecer o que queremos dizer ao tratarmos de afetividade, sob pena do conceito ser reduzido apenas à ideia de emoção como algo interno do sujeito, sem maiores implicações políticas. Ideia esta, que queremos desde logo afastar.

Remetendo ao tema, afirma Brandão (2012, p.7-8):

Mas de que afetividade estamos falando? Certamente não se trata aqui do retorno a uma emocionalidade solipsista, aprisionada na intimidade de cada pessoa, mas nos sentimentos ativos, que só podem ser produzidos no bom encontro entre sujeitos. Falamos, pois, de uma afetividade ética e política, inconcebível sem a presença do outro. Daí a necessidade de se construírem espaços sociais de construção subjetiva e de fortalecimento da individualidade e da sociabilidade.

Desta forma, antes de qualquer coisa, é preciso esclarecer que o sentido que queremos dar a esta afetividade passa muito além do conceito de emoção, como coloquialmente nos referimos aos sentimentos internos, individuais e nem sempre externalizados ou compartilhados. Aqui queremos referir afeto como a possibilidade de troca entre sujeitos e com os corpos políticos e a maneira pela qual esta troca afeta a vida no planeta. Portanto, não nos interessa a visão maniqueísta de afeto como antagônico à razão, mas a afetividade como possiblidade de ação. Diga-se de passagem, que esta visão de que a razão e a emoção são antagônicas não se constrói no pensamento filosófico clássico, pois na base do pensamento Platônico, por exemplo, somos regidos pela razão, ainda que o desejo também faça parte de nossa existência. (BRANDÃO, 2012)

Dito isto, não se pretende traduzir afeto necessariamente como positivo, mas também os afetos presentes no conflito, na luta de classes, na divisão injusta do trabalho e no desenho social inferiorizado e excludente da mulher, por exemplo. Interessa-nos, portanto, estabelecer como tais afetos constroem e desconstroem a sociedade que nos cerca e como estes são capazes de contribuir para um mundo sustentável ou insustentável. Não se imagine que tal visão é de menos importância, pois, o reconhecimento de tais afetos e o estudo de como eles se apresentam socialmente é fundamental para a consecução de uma vida de plenitude, de equilíbrio a que nos remete a ideia de sustentabilidade.

Afeto é uma força poderosa, capaz de movimentar sujeitos individuais e coletivos nas mais diversas direções a partir da condução de poder, do direcionamento de vontades e do reconhecimento da energia transformadora da ação.

revista brasileira educação ambiental 
Esta importância do afeto aparece de forma ainda mais clara quando se percebe a possibilidade de controle político destes afetos, num mundo onde a individualidade é cada vez mais ignorada e muitas vezes desencorajada. Num mundo onde os sujeitos são vistos como padronizados, a forma de circulação destes afetos pode conduzir a realidades não desejadas pelos detentores do poder. Nestes termos, ainda Brandão (2012, p.15), ao citar Bader Sawaia, arremata que:

Controlar a expressão radicalmente humana dos afetos é, indubitavelmente, uma forma poderosa de fazer o mesmo com os cidadãos, cujo sentir pode deixar de exprimir a sua condição de sujeito que deseja e que, por isso mesmo, também se frustra, inquieta-se e, em muitos momentos, sofre, para se tornar a exteriorização de uma ideologia alienadora, que transforma os cidadãos em indivíduos passivos e obedientes.

Assim, para discutir afirmação de individualidade como pressuposto de sustentabilidade, inserindo estas questões no ambiente da família, é necessário discutir os corpos políticos e a maneira como eles nos afetam, para, percebendo as possibilidades e modos pelos quais somos afetados e discutir maneiras de redefinir posicionamentos individuais e coletivos, que aumentem a autonomia dos sujeitos.

Segundo Safatle (2015, p. 16),

talvez precisemos partir da constatação de que sociedades são, em seu nível mais fundamental, circuitos de afetos. Enquanto sistema de reprodução material de formas hegemônicas de vida, sociedades dotam tais formas de força de adesão ao produzir continuamente afetos que nos fazem assumir certas possibilidades de vida a despeito de outras (...). Há uma adesão social construída através das afecções. Nesse sentido, quando sociedades se transformam, abrindo-se à produção de formas singulares de vida, os afetos começam a circular de outra forma, a agenciar-se de maneira a produzir outros objetos e efeitos.

É basicamente a partir daqui que se pretende esclarecer como estão presentes estes afetos em diversas estruturas sociais hegemônicas, conduzindo a pouca ou nenhuma individualização. Se tomarmos como base a própria discussão sobre sustentabilidade e desenvolvimento sustentável, seria saudável pensar de que forma populações menos favorecidas afetam e são afetadas por modelos econômicos que padronizam modos de produção nos quais estas populações não estão inseridas.

Mais profundamente em espaços individuais e coletivos, que tipo de afetos se estão construindo e como tais afetos são capazes de modificar 
estruturas milenares de poder, como por exemplo o patriarcado, a divisão sexual do trabalho e outras questões igualmente importantes; Mais ainda, de que forma estes afetam, inviabilizando o acesso de determinados grupos a uma vida sustentável.

É na perspectiva de observação dos indivíduos como um corpo que se analisa os afetos dentro da família. Mesmo como um corpo social coeso, a família se constitui de sujeitos individuais, que consigo trazem afetos múltiplos que, influenciados externa e internamente, constituem formas de potencialização diversas.

A noção de si está intimamente ligada ao reconhecimento do outro. É outro que nos reconhece e, ao nos reconhecer nos constitui. Este processo, porém, não se realiza individualmente. Se perfaz numa intrincada teia de relações em que o sujeito se reconhece e a partir de onde se encontra, inventa e reinventa compartilhando sua vida social e definindo a si mesmo.

É certo que há um modelo fixo de família que nos serve de base no Ocidente, qual seja o modelo de família romana, patriarcal e de forte base religiosa. Modernamente, porém paulatinamente, vem se abandonando a ideia de existência unificada de um modelo familiar. Tem-se cada dia menos privilegiado a forma em detrimento do conteúdo e compreende-se que cada sujeito em particular constitui-se a partir do espaço em que se encontra, levando em consideração não só espaço geográfico, mas sobretudo o espaço político. Afirma Todorov (2012, p.23) ao se referir ao indivíduo: que "ao contrário da imagem do homem que encontramos na base da doutrina neoliberal, este não é o produto da sua própria vontade, mas constitui-se, sempre e apenas, a partir do meio familiar e social em que nasce". Num espaço familiar tão múltiplo como o que é experimentado atualmente, se faz necessário investigar de que modo estes sujeitos se constituem e se influenciam internamente e como são capazes de influenciar o meio externo a partir de suas unidades familiares.

Ao discutirmos relações sociais, como aquelas que se dão entre o indivíduo e a sociedade, a família aparece como mediadora desta relação, sendo responsável em última instância pelos ajustamentos entre estes dois atores. Deste modo, a importância da família no processo de pertencimento social é inegável, uma vez que é no seio da família que se instauram inicialmente os processos de adequação social dos sujeitos. É na base familiar que se assentam a reprodução dos padrões culturais vigentes, bem como a referência para a construção subjetiva de seus membros, que sempre a terão como referencial. É na família que se constroem os laços de parentesco, afeto, pertencimento e vínculos.

A partir da II Guerra Mundial, a família passa por uma profunda aceleração da individualização. Esta individualização, entretanto, aparece como mais um desafio para a mulher. A modificação no mercado de trabalho, a adaptação à realização jurídica de uma igualdade formal e a própria necessidade de organizações feministas atuantes demonstram que a produção 
desta individualização era na verdade a produção do indivíduo masculino (DUARTE, 1995).

Ainda nos reportando ao modelo familiar ocidental e cristã de base romana, temos que entre os romanos, a mulher ao casar abandona o culto aos seus antepassados e passa a cultuar os antepassados do marido (Coulanges). Nesta ótica, percebe-se claramente uma situação de submissão.

Deste modo, a família reproduz em seu interior a normatização posta pelo Estado, definida inicialmente por relações hierárquicas marcadas pela autoridade patriarcal, assentada primitivamente na religião. A religião foi, portanto, a norma constitutiva da família antiga (Coulanges). Ora, a família patriarcal reserva ao indivíduo masculino um lugar social distante do doméstico, este relegado à mulher e aos filhos. O lugar da mulher é fundamental nesta família por conta da maternidade; papel que não pode ser atribuído ao homem e pelo qual ela é a responsável direta, evidenciando-se claramente a divisão dos papéis pelo gênero. Porém, este destaque para o papel essencial da mulher com a maternidade, apesar de parecer prestigioso, na verdade esconde uma profunda repressão à autonomia feminina, que será sempre culpada por eventualmente não exercer o dever que a ela cabe.

Dentro da família, à mulher coube o papel prioritário de cuidado da prole e realização dos trabalhos domésticos que, com as modificações contemporâneas passou a ser partilhado também pelos homens, uma vez que hoje a mulher participa cada vez mais ativamente do mercado de trabalho, embora não em condição de igualdade. O fato é que coube à família construir uma identidade feminina, na medida em que na escala social os homens sempre se destacam pois os chamados trabalhos masculinos são mais valorizados que os trabalhos femininos, geralmente voltados à casa e ao cuidado dos demais membros da família, mesmo quando atuante no mercado de trabalho, quase sempre cabe à mulher este acúmulo de funções.

No Brasil, com o advento da República muitas modificações importantes se deram no que diz respeito à família e ao papel feminino, sobretudo na passagem do século XIX para o século $X X$.

Procurando encampar um modelo de modernização, preconiza-se um novo modelo de família, onde a vontade individual ganha mais espaço, e de certa forma se distancia um pouco das imposições patriarcais, sobretudo no que diz respeito à escolha do cônjuge pois este autoritarismo próprio de sociedades escravocratas não tinha lugar na modernidade. A família passa a ser vendida, nos moldes do pensamento europeu, como um lugar de sossego, de aconchego, onde se poderia fugir dos problemas do mundo exterior.

Nesta perspectiva, novamente surge para a mulher uma nova demanda: a de se adequar ao modelo novo de família. Sobre o tema discorrrem Pinsky e Pedro (2012 p.17): 
A 'nova família' também exigia uma 'nova mulher': uma mãe dedicada que dispensava especial atenção ao cuidado e à educação dos filhos (não recorrendo mais às amas de leite, por exemplo), responsabilizando-se também pela formação moral das crianças. Essa nova mulher seria também a esposa afetiva, ainda submissa ao marido, mas não completamente sem voz. Desobrigada agora de qualquer trabalho produtivo, a mulher estaria voltada inteiramente aos afazeres do lar, o espaço feminino por excelência, ao passo que o espaço público seria o domínio dos homens(...)ao contrário do que poderíamos supor, esse novo modelo de família, que transformara a mulher na 'rainha do lar' manteve a mesma hierarquia com relação aos papéis masculinos e femininos, com o homem como cabeça da casa e da família e a mulher como subalterna e dependente.

Percebe-se que a família chega à dita modernidade, mas perpetua no que diz respeito à figura feminina, um modelo extremamente restrito e excludente. É interessante notar que as mulheres, que exercem um papel muito significativo na socialização das crianças, em razão da maternidade, reproduzem este modelo diferenciado de moral sexual.

Conforme Bourdieu (1999), a dominação masculina é uma forma de dominação sobretudo simbólica e sendo assim, só se faz com a colaboração dos dominados. As mulheres legitimam esta dominação masculina reproduzindo-a no processo de socialização de seus filhos, tanto homens quanto mulheres. Isto aparece claramente na ideia de recato, incentivada entre às mulheres, em detrimento de um papel de conquistador e sexualmente experiente que se incentiva quanto aos homens.

A família é então este espaço de socialidade onde buscam-se satisfazer as necessidades afetivas, materiais e sociais simbólicas, ancoradas em ordenações legais, religiosas, sexuais e econômicas, que se sedimentam e instituem o modo de viver e mover-se no mundo. Apesar da crescente inserção da mulher no mercado de trabalho, da elasticidade da família promovendo novos arranjos familiares, bem como as transformações econômicas e sociais, a urbanização e as novas tecnologias, os papéis definidos culturalmente na divisão do trabalho entre os sexos não se alterou significativamente. Isto se evidencia mais claramente nas populações menos privilegiadas social e economicamente.

Ao fazer a intersecção entre os papéis masculino e feminino e como estes se põem no que diz respeito à questão da sustentabilidade, nos deparamos com uma ideia extremamente pulsante e atual que é o ecofeminismo, que a respeito do surgimento do tema e seu conceito nos pontuam Trevisan e Flores (2015 P.12),

o termo ecofeminismo teria sido utilizado pela primeira vez em 1974, por Françoise d'Eaubonne, que, em 1978, fundou, na França, o movimento Ecologia e Feminismo. A relação entre ciência, mulher e 
natureza estaria entre as primeiras preocupações do movimento ecofeminista. Destaca-se no movimento que ecologia é um assunto feminista, mas que as semelhanças entre feminismo e ecologia têm sido esquecidas pela ciência ecológica, e essa vertente do movimento feminista, unindo o movimento das mulheres com o movimento ecológico, traz uma nova visão de mundo, desvinculada da concepção socioeconômica e de dominação.

A correlação para forjar o tema é feita levando em consideração as semelhanças existentes entre feminismo e ecologia. Tal ligação pressupõe que tanto as mulheres quanto a natureza foram historicamente alvos da agressão do sistema patriarcal que baseia o modelo capitalista de produção. Assim, sendo ambas exploradas, a luta do ecofeminismo é pela libertação da mulher da opressão, a busca pelo lócus feminino na luta ecológica e a consequente libertação da natureza.

Existe uma relação mística entre a mulher e a terra e o dar à luz seria uma variante humana da fertilidade da terra. $E$ assim todas as experiências religiosas relacionadas com a fecundidade e o nascimento têm uma estrutura cósmica. Não sem razão, todas as divindades primitivas ligadas à terra são femininas (ELIADE, 1992).

Nas suas raízes mais profundas, a terra e seu cuidado, seriam historicamente preocupações femininas, das quais a mulher teria sido desapropriada pelo homem a partir da inserção de práticas como a irrigação e a utilização do arado.

Nesta lógica, a libertação feminina da opressão e a consequente libertação da terra da exploração desenfreada, passaria indubitavelmente pela superação da dominação que impõe às mulheres as consequências mais nefastas da falta de sustentabilidade. Estas consequências, para além das questões de ordem socioeconômica, poderiam ser sentidas no próprio corpo feminino, atingido por resíduos tóxicos dos produtos industrializados e condições insalubres de trabalho, por exemplo.

Dentro da família a lógica da divisão entre os papéis masculinos e femininos ainda é muito presente, conduzindo à insustentabilidade das relações dentro dela, uma vez que na perspectiva ampliada da sustentabilidade como equilíbrio, é impossível falar de sustentabilidade em espaços de opressão e dominação do outro. É ainda impossível imaginar uma sustentabilidade que não possua um circuito de afetos alegres, vez que sendo implicados sempre por afetos de tristeza, não poderão os sujeitos produzirem as mudanças necessárias para mudar seu estado de coisas interior e consequentemente o mundo que o rodeia. 


\section{Conclusão}

Sustentabilidade afetiva, como inserida dentro da dimensão política e social da sustentabilidade pressupõe a superação de fatores internos e externos sedimentados durante séculos, construindo verdades quase que absolutas, que são replicadas e atualizadas no rito diário vivido dentro da unidade social primária mais significativa para o sujeito, que é a família. Este grupo é afetado todos os dias e sob diversas óticas pelos mais diferentes tipos de afeto. Internamente, entre seus membros, é afetado pela diminuição histórica da importância do papel da mulher no seio familiar, é afetado ainda pelo paradigma pós-moderno da pouca ou nenhuma atenção aos membros idosos dos grupos familiares. $E$ ainda influenciado pela individualidade exacerbada como marca do tempo presente, somente para tratar de alguns destes afetos circulando entre os membros. Não se pode esquecer, ainda das influências externas de corpos políticos, que afetam diretamente este grupo, causando insustentabilidade. Os afetos políticos, construídos pela negligência dos governos quando não disponibilizam a estes grupos acesso aos direitos mínimos para uma sobrevivência digna, exemplificado na pouca ou quase nenhuma condição de desenvolvimento pela falta de serviços minimamente eficientes em saúde, educação, acesso á justiça e de forma mais coletiva, na deficiência na criação, implantação e gerenciamento de políticas públicas que fomentem inclusão e autonomia e estes sujeitos nas diversas áreas de sua vida.

O horizonte de um espaço sustentável, equilibrado e produtor de afetos alegres só é possível de ser engendrado a partir do reconhecimento por parte dos corpos políticos, que as ações praticadas por eles enquanto detentores do poder decisório afetam individual e coletivamente os sujeitos causando a impossibilidade de desenvolvimento em seu sentido mais ampliado. A falta de educação e consequentemente a falta de compreensão de sua importância no processo decisório, conduz a sujeitos quase sem nenhuma condição de participar ativamente dos processos decisórios através do exercício da cidadania, que passa neste contexto a ser apenas ficta, posto que os cidadãos não são capazes de exercê-la com consciência.

Não é mais possível pensar sustentabilidade com foco apenas nas questões de ordem meramente ecológicas. O meio ambiente é constantemente modificado pelo homem no seu exercício de produção de cultura e, nesse contexto, convém tratar dos produtores do espaço quando se pretende modificar este espaço. Uma política de sustentabilidade com foco no sujeito humano, afetivo, afetado e produtor de realidades, parece se descortinar como a verdadeira e única possibilidade de se alcançar sustentabilidade. 


\section{Referências}

BOURDIEU, P. A dominação masculina, Rio de Janeiro, Bertrand Brasil, 1999.

BRANDÃO, I.R. Afetividade e Transformação Social, Ceará, Edições universitárias UVA, 2015.

BRUSECKE, F.; FERREIRA, L.C. VIOLA, E. (orgs.) Desestruturação e desenvolvimento. Incertezas de sustentabilidade na globalização. Campinas/SP: Unicamp, 1996.

BURSZTYN, M. A difícil sustentabilidade: política energética e conflitos ambientais. Rio de Janeiro, Ed. Garamond, 2001.

DELEUZE, Gilles. Spinoza: filosofia prática. São Paulo: Escuta, 2002.

DUARTE, L.F.D. Horizontes do indivíduo e da ética no crepúsculo da família. Disponível em: https://books.google.com.br/books?hl=ptBR\&Ir=\&id=08-Rn3Gm8wC\&oi=fnd\&pg=PA27\&dq $=+0+$ individuo + na + fam $\%$ C3\%ADlia\&ots=xEeLLWIrhF\&sig=7j0uRTgwgsGlwpS071eRRnKH as\#v=onepa ge\&q=0\%20individuo\%20na\%20fam\%C3\%ADlia\&f=false

ELIADE, M. O sagrado e o profano. São Paulo, Martins Fontes, 1992.

ESPINOZA, B. Ética. Belo Horizonte: Autêntica, 2009.

FLORES, B.N.; TREVIZAN, S.D.P. Ecofeminismo e comunidade sustentável. Revista estudos feministas. Florianópolis 2015 disponível em: http://www.ieg.ufsc.br/admin/downloads/artigos/09032015035123ecofeminismo.pdf. Acesso em 27 de janeiro de 2018

FOLADORI, G. Limites do desenvolvimento sustentável. São Paulo: Editora da Unicam p.2001

FURTADO, C. Cultura e Desenvolvimento em Épocas de Crise. Rio de Janeiro: Paz e Terra, 1984. .

GUATTARI, F.; ROLNIK, S. Micropolítica: Cartografias do Desejo. Petrópolis/RJ, Vozes, 1999.

LEFF, E. Racionalidade ambiental: a reapropriação social da natureza. Rio de Janeiro, Ed. Civilização Brasileira , 2006.

PINSKY, C.B.; PEDRO, J.M. Nova história das mulheres no Brasil. São Paulo, Editora Contexto, 2012

RADOMSKY, G.; PEÑAFIEL, A. Desenvolvimento e Sustentabilidade. Curitiba. Ed Intersaberes, 2013

SACHS I. Desenvolvimento: includente, sustentável, sustentado. Rio de Janeiro, Garamond, 2004.

SACHS, I. Espaços, Tempos e Estratégias do Desenvolvimento. São Paulo: Vértice.1986 
SACHS, I. Caminhos para o desenvolvimento sustentável. Rio de Janeiro: Garamond, 2002.

SAFATLE V. O circuito dos afetos. Corpos políticos, desamparo e o fim do indivíduo. São Paulo Ed. Autêntica,2015.

SEN Amartya. Desenvolvimento como liberdade. São Paulo Cia das Letras ,2000.

TODOROV, T. Os inimigos íntimos da democracia. São Paulo, Companhia das letras, 2012.

VEIGA, J.E. Desenvolvimento rural: o Brasil precisa de um projeto. Texto para Contag 1988. 55 paginas. Disponível em: http://www.contag.org.br acesso em 11 de outubro de 2017.

VEIGA, José Ely da, Desenvolvimento sustentável: o desafio do século XXI. Rio de Janeiro: Garamond, 2008.

VIOLA, E.; FRANCHINI, M. Sistema internacional de hegemonia conservadora: o fracasso da Rio +20 na governança dos limites planetários. Ambiente \& Sociedade (Online) , v. 15, p. 01-18, 2012. 